\title{
Superovulation in cows synchronized with two different progesterone+oestradiol protocols
}

\author{
Bülent Bülbül', Mesut Kirbaş', Şükrü Dursun' and Mehmet Köse² \\ 'Bahri Dağdaş International Agricultural Research Institute, Konya, Turkey, '2Department of Obstetrics and Gynecology, \\ Veterinary Faculty, Dicle University, Diyarbakır, Turkey
}

\begin{abstract}
A total of 26 Brown Swiss cows were used to compare the synchronization and superovulatory response of follicle stimulating hormone treated cows that were synchronized with progesterone+oestradiol valerate or benzoate. Control cows $(n=8)$ were superstimulated with follicle stimulating hormone using twice daily injections with decreasing doses from day 10-13 after determined reference oestrus. Cows in treatment groups were received either ear implant $(n=9)$ containing norgestomet+oestradiol valerate or progesterone releasing intravaginal device $(n=9)$ containing progesterone+oestradiol benzoate, at random stage of the oestrus cycle, for 9 days. Seven days after the implant and progesterone releasing intravaginal device insertion, follicle stimulating hormone was injected as described in the control group. There was no significant difference between the groups for superovulation responses. In conclusion, both protocols synchronized the oestrus cycle in follicle stimulating hormone treated cows and, any of the protocols evaluated in this study can be used as a pretreatment for superstimulation started on the seventh day of the implant or progesterone releasing intravaginal device insertion in Brown Swiss cows.
\end{abstract}

Keywords: cow, oestradiol benzoate, oestradiol valerate, progesterone, superstimulation

Abbreviations: FSH: follicle stimulating hormone, GnRH: gonadotropin-releasing hormone, PRID: progesterone releasing intravaginal device

Archiv Tierzucht 56 (2013) 15, 160-168

Received: 16 February 2012

doi: $10.7482 / 0003-9438-56-015$

Accepted: 16 May 2012

Corresponding author:

Online: 1 March 2013

Bülent Bülbül; email: bulbulent@hotmail.com

Bahri Dağdaş International Agricultural Research Institute, Animal Breeding and Biotechnology,

P.K.:125, Karatay, Konya, TR42020, Turkey

(c) 2013 by the authors; licensee Leibniz Institute for Farm Animal Biology (FBN), Dummerstorf, Germany.

This is an Open Access article distributed under the terms and conditions of the Creative Commons Attribution 3.0 License (http://creativecommons.org/licenses/by/3.0/). 


\section{Introduction}

Success of embryo transfer depends on stimulating follicular growth, ovulation of these developed follicles, fertilization of oocytes, collection and transfer of embryos, establishment of pregnancy and finally obtaining many calves (Armstrong 1993, Mikkola et al. 2005, Novotny et al. 2005). Superovulation response is very important for this aim and it is one of the most critical stages in embryo transfer protocols. For this respect, it is very important to know about the factors effecting superovulation response and elimination of the negative situations (Andrade et al. 2003).

There are many researches in which greater superovulatory responses were reported when superstimulatory treatments were initiated 8-12 days after reference oestrus (Lindsell et al. 1986, Rajamahendran \& Calder 1993). Gonadotrophin treatment started on 8-12 days after oestrus is based on the knowledge of emergence of the second follicular wave in these days (Hasler 1992, Huhtinen et al. 1992, Bungartz \& Niemann 1994, Sato et al. 2005). However, the day of emergence of the second follicular wave has been shown to differ between twoand three-wave cycles and individual animals (Sirois \& Fortune 1988, Webb \& Armstrong 1998). It is reported that, only $20 \%$ of the oestrus cycle is available for initiating treatment at the time of follicular wave emergence. That is, $80 \%$ of the oestrus cycle is not conductive to an optimal superovulatory response (Bó et al. 2004). Some new protocols have developed to obviate this problem by exogenous control of both luteal and follicular function (Gordon 2005). In recent years, progestagen/progesterone+oestradiol combinations have been used to control of follicle wave emergence. This application also offers the advantage of initiating superovulatory treatments at a time that is optimal for follicle recruitment, regardless of the stage of the oestrus cycle (Nasser et al. 1993, Baracaldo et al. 2000). These new protocols permit the initiation of superstimulatory treatments at a self-appointed time (Bó et al. 2006). However, the interval to emergence of a new follicular wave is quite variable in cows treated with different oestradiol preparations and, initiation day of gonadotrophin treatment following these various preparations has a great importance on superovulation response (Colazo et al. 2005). In a study, superstimulatory treatment in cows initiated 4 days after treatment with $2.5 \mathrm{mg}$ oestradiol benzoate or $5 \mathrm{mg}$ or $2.5 \mathrm{mg}$ oestradiol-17 $\beta$ +progesterone resulted in superovulatory responses comparable to those initiated 8-12 days after reference oestrus (Mapletoft \& Bó 2004). However, Mapletoft et al. (1999) reported less synchronous emergence of a follicular wave and a lower superovulatory response in cows superstimulated 5 days after treatment with oestradiol valerate and $3 \mathrm{mg}$ norgestomet. In a previous study, synchronization of the oestrus cycle using ear implant containing progesterone+oestradiol valerate and gonadotrophin injection for 4 days started on day 7 of the progesterone+oestradiol treatment was successful and, comparable superovulatory results determined with the protocol in which superstimulation was initiated on day 10 after spontaneous reference oestrus (Bülbül et al. 2010).

Because of the probability of difference between oestradiol valerate and oestradiol benzoate in synchronizing oestrus, the objective of the present study was to compare the synchronization success and superovulatory response of gonadotrophin injection started on the seventh day of the progesterone+oestradiol valerate or progesterone+oestradiol benzoate as a pretreatment for superstimulation in Brown Swiss cows. 


\section{Materials and methods}

Animals

A total of 26 lactating Brown Swiss cows, aging 3-8 years were randomly allocated into three groups. The animals were selected taking the criterions listed as followed:

a) no dystochia and retained fetal membranes in previous calving;

b) no prulent discharge during vaginal examination;

c) 50-120 days post-partum;

d) have shown oestrus at least twice, and no artificial insemination or mating after previous calving.

The cows were kept in similar conditions of handling and feeding and fed with a ration composed of corn silage, alfalfa hay and a concentrate-mineral mix, had ad libitum access to fresh water and housed in a free-stall confinement facility.

\section{Experimental protocol}

Experimental desing was illustrated in the Figure 1. In the Control group $(n=8)$, cows were superovulated with follicle stimulating hormone (FSH) (Folltropin-V, total: $400 \mathrm{mg} \mathrm{NIH}-$ FSH-P1, Bioniche Animal Health Inc., Ontario, Canada), from day 10-13 (spontaneous reference oestrus=day 0$)$, using twice daily injections with decreasing doses $(4,4,3,3,2,2,1,1 \mathrm{ml})$ and intramuscularly injected $150 \mu \mathrm{g}$ of D-cloprostenol (Dalmazin, Vetaş, İstanbul, Turkey) with the fifth FSH injections.

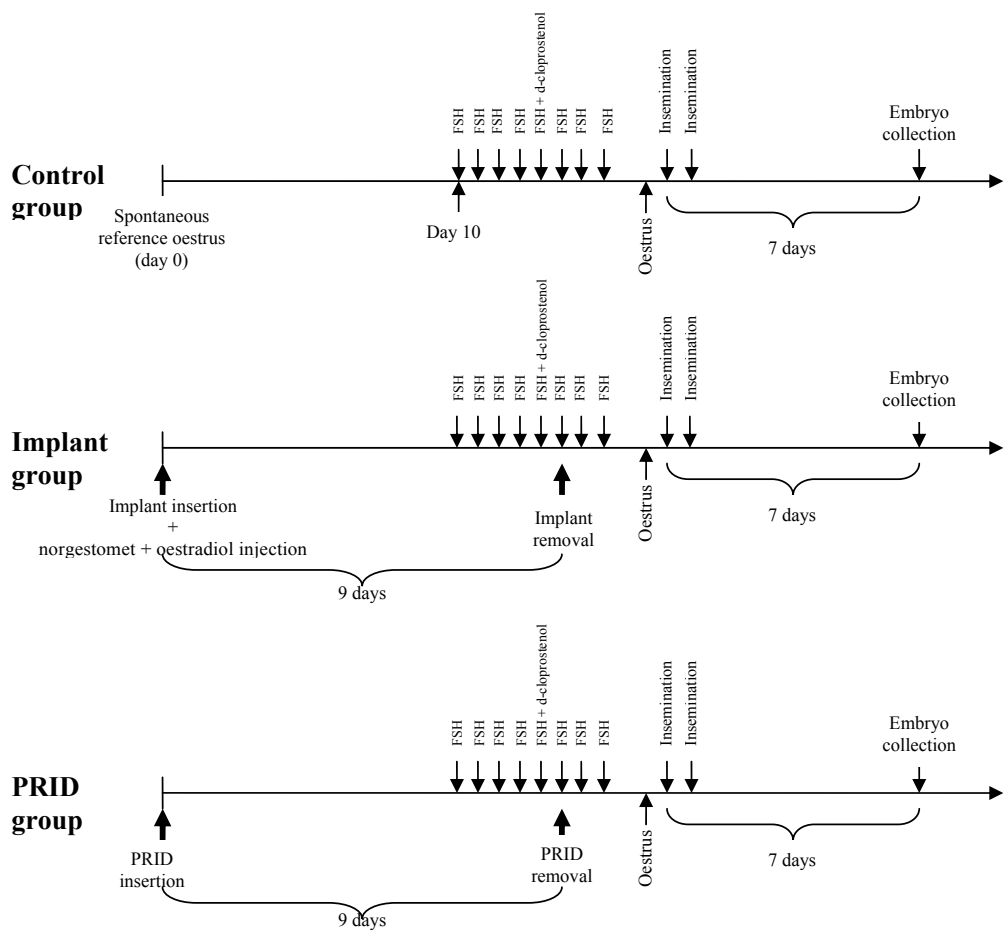

Figure 1

Experimental design 
In the treatment groups, cows were received either ear implants (Implant group, $n=9$, Crestar, Intervet, İstanbul, TURKEY) containing $3 \mathrm{mg}$ norgestomet $+5 \mathrm{mg}$ oestradiol valerate or progesterone releasing intravaginal device (PRID) (PRID group, $n=9$, PRID, Sanofi Doğu llaç A.Ş., Istanbul, Turkey) containing $1.55 \mathrm{gr}$ progesterone $+10 \mathrm{mg}$ oestradiol benzoate at random stage of the oestrus cycle. Ear implants were inserted to the ear subcutaneously and PRIDs were placed to the anterior vagina of each cow for 9 days. Cows in the Implant group were also treated intramuscularly with $3 \mathrm{mg}$ norgestomet $+5 \mathrm{mg}$ oestradiol valerate at the time of implant insertion. On the seventh day of the implant and PRID insertion, FSH was injected for 4 days as described in the control group. D-cloprostenol at the dosage of $150 \mu \mathrm{g}$ was injected to the cows in the treatment groups with the fifth FSH injections.

Observation of oestrus was initiated following the last FSH injection. The cows in all groups were observed for oestrus signs (visual observation of standing heat, vaginal discharge) three times a day for $30 \mathrm{~min}$ each time and, oestrus was confirmed by rectal palpation of fluctuant dominant follicles and uterine tonus. All cows were artificially inseminated twice by a skilled technician $12 \mathrm{~h}$ and $24 \mathrm{~h}$ after the onset of oestrus and, were inseminated using frozen-thaved semen $\left(20 \times 10^{6}\right.$ spermatozoa/straw with about $60 \%$ progressive motility after thawing) throughout the experiment.

Superovulatory response was assessed by rectal palpation and ultrasonography (PIE Medical Falco 100; Esaote, Maastricht, The Netherlands) 7 days after the first insemination, with regard to the number of corpora lutea in the ovaries using a $7.5 \mathrm{MHz}$ linear-array transducer. The ovaries were scanned in several planes to identify all corpora lutea. Embryo flushes were performed non-surgically, 7 days after the first insemination, using $1000 \mathrm{ml}$ ringer lactate (Ringesol, Vilsan, Ankara, Turkey) containing $1 \%$ fetal calf serum (N-4267, Sigma-Aldrich, St. Louis, MI, USA) and 0.1\% kanamicyn sulfate (Kanovet, Vetaş, İstanbul, Turkey) with a two-way disposable Foley catheter, inserted into the uterine horn through the cervix and, the ova/embryos were collected. The recovered lavage fluid was filtered through $72 \mu \mathrm{m}$ filter (Emcon filter, Minitüb GmbH, Tiefenbach, Germany). Quality of the recovered embryos was assigned under a stereomicroscope at 20-fold magnification according to the morphological criteria of quality and viability determined by International Embryo Transfer Society (Wright 1998). Embryos were classified as grade 1 (excellent or good), grade 2 (fair), grade 3 (poor) and degenerated embryos and unfertilized oocytes. Grade 1, 2 and 3 embryos were defined as transferable.

\section{Statistical analyses}

The Mann-Whitney nonparametric test was used to compare the mean numbers of corpora lutea, total ova and embryos, grade 1,2 and 3, transferable and degenerated embryos and unfertilized ova between the groups. Last FSH injection-oestrus intervals were compared using analysis of variance (One-way ANOVA). All analyses were carried out using a statistical analysis system configured for computer (MINITAB rel. 12.1, Minitab Inc., State College, PA, USA). The differences were considered significant at $P<0.05$. 


\section{Results}

All cows used in this trial showed signs of oestrus within $24 \mathrm{~h}$ of the last FSH injection. Last FSH injection-oestrus intervals were similar in groups (Table 1).

Recovery rates, the mean numbers of corpora lutea, total ova and embryos, grade 1, 2 and 3 , transferable and degenerated embryos and unfertilized ova in Control, Implant and PRID groups were summarized in Table 1. There was no significant difference between the groups in any of the criterions that were evaluated. In Implant group, the number of corpora lutea and total ova and embryos were higher whereas the number of transferable embryos was lower than the other groups. However, the differences among groups were not significant.

Table 1

Recovery rates, the mean last FSH injection-oestrus intervals, numbers of corpus luteum, total ova and embryos, transferable, grade 1, 2 and 3 and degenerated embryos, and unfertilized ova in control, implant and PRID groups ( \pm SEM)

\begin{tabular}{lccc}
\hline & Control & Implant & PRID \\
\hline Last FSH injection-oestrus interval, $\mathrm{h}$ & $18.0 \pm 0.0$ & $16.67 \pm 0.88$ & $18.0 \pm 0.0$ \\
Numbers of: & 8 & & \\
Cows & $8.4 \pm 1.6$ & 9 & 9 \\
Corpora lutea & $5.9 \pm 2.0$ & $9.1 \pm 1.8$ & $7.3 \pm 2.0$ \\
Total ova and embryos & 70 & $6.3 \pm 1.4$ & $6.1 \pm 2.2$ \\
Recovery rates, \% & $4.6 \pm 1.8$ & 69 & 84 \\
Transferable embryos & $2.9 \pm 1.5$ & $4.4 \pm 1.1$ & $4.8 \pm 1.6$ \\
Grade 1 & $1.1 \pm 0.4$ & $2.1 \pm 0.6$ & $2.9 \pm 1.2$ \\
Grade 2 & $0.6 \pm 0.3$ & $1.4 \pm 0.5$ & $1.6 \pm 0.7$ \\
Grade 3 & $0.6 \pm 0.3$ & $0.9 \pm 0.4$ & $0.3 \pm 0.2$ \\
Unfertilized ova & $0.6 \pm 0.3$ & $0.4 \pm 0.2$ & $0.6 \pm 0.2$ \\
Degenerated embryos & & $1.4 \pm 0.7$ & $0.8 \pm 0.6$ \\
\hline
\end{tabular}

\section{Discussion}

Treatments using oestradiol and progesterone have been widely used over the past years in oestrus synchronization (Burke et al. 1999, Martinez et al. 2002). In these protocols, a progestogen/progesterone device is inserted for 7-12 days and oestradiol and progestogen/ progesterone is administered on day 0 to synchronize follicular wave emergence (Diskin et al. 2002). Prostaglandin is injected the day before or at the time of device removal to ensure luteolysis (Lemaster et al. 1999). There are so many reports that achieved successful synchronization results using this protocol (Cavalieri et al. 1997, Penny et al. 1997, Ryan et al. 1999, Bülbül \& Ataman 2006). The majority of cattle are expected to exhibit oestrus 24-48 h after removal of implants or intravaginal devices (Penny et al. 1997, Lemaster et al. 1999). It is reported that this protocol can be used to synchronize oestrus cycle as a pretreatment for superstimulation started 4 days after progesterone+oestradiol treatment Mapletoft \& Bó (2004). The results of a previous study (Bülbül et al. 2010) led us to compare the synchronization success and superovulation response of two different protocols using progesterone+oestradiol and, superstimulation started on the seventh day of the progesterone+oestradiol application with the conventional superovulation protocol which 
was initiated on day 10 after oestrus in FSH superstimulated cows. In the current study, all cows in groups showed the signs of oestrus within $24 \mathrm{~h}$ after the last FSH injection. Last FSH injection-oestrus intervals were not significantly different between groups. In addition to the oestrus synchronization success in treatment groups was similar to that in Control group, there was no significant difference between treatment groups in synchronization.

It is reported that various factors influenced the superovulatory response of cattle (Kafi \& McGowan 1997). One of these factors is the ovarian status at the time of gonadotrophin treatment and the timing of treatment with respect to the oestrus cycle (Colazo et al. 2005). It has shown that gonadotrophin treatments must be initiated at the expected time of the follicular wave emergence for optimizing superovulatory response (Adams et al. 1994, Mapletoft et al. 2009). Because of the day of the second follicular wave varies among cows and between cycles with two and three follicular wave (Sirois \& Fortune 1988), synchronization of the follicular wave emergence prior to initiation of superstimulatory treatments is suggested (Gordon 2005). Progesterone+oestradiol treatment is said to cause a new follicular wave emergence within 3-6 days (Bo et al. 1995, Caccia \& Bó 1998, Mapletoft et al. 1999, Diskin et al. 2002). Oestradiol not only has been used to induce luteolysis in progestin-based protocols, but also has been shown to suppress antral follicle growth by suppressing circulating concentrations of FSH. Following metabolism of oestradiol, FSH surges and a new follicular wave emerges (Price \& Webb 1988, Garcia \& Salaheddine 2001). It is reported that the interval to emergence of a new follicular wave is quite variable in cows treated with different oestradiol preparations (Burke et al. 1999, Colazo et al. 2005). For this reason, initiation day of gonadotrophin treatment following these various preparations has a great importance on superovulation response (Colazo et al. 2005). In previous studies, Mapletoft \& Bó (2004) reported comparable superovulatory results using superstimulatory treatment 4 days after treatment with $2.5 \mathrm{mg}$ oestradiol benzoate or $5 \mathrm{mg}$ or $2.5 \mathrm{mg}$ oestradiol-17 $\beta$ +progesterone to those initiated 8-12 days after estrus while Mapletoft et al. (1999) reported lower superovulatory response in cows superstimulated 5 days after treatment with $5 \mathrm{mg}$ oestradiol valerate $+3 \mathrm{mg}$ norgestomet. In an other study, Bülbül et al. (2010) reported similar superovulatory responses in cows superstimulated 7 days after an ear implant insertion containing 3 mg norgestomet $+5 \mathrm{mg}$ oestradiol valerate with conventional protocol in which superstimulation is started on day 10 after oestrus. In this study, superstimulatory responses in treatment groups were similar to each other, and also similar with Control group. This result may be originated from a new follicular wave emergence in cows treated with implant and PRID in the same manner. Similar to our results, there are some other researchers who reported progesterone+oestradiol treatment caused a new follicular wave emergence for implant (Bo et al. 1995, Martinez et al. 2000) and PRID (Bridges et al. 1999, Cavalieri et al. 2003) application.

The most important aim of this study was to compare the embryo quality obtained from different synchronization protocols. There was no significant difference among groups for the numbers of transferable embryos. In addition, the numbers of grade 1, 2 and 3 embryos were also similar among groups. In the light of the data obtained for embryo quality, we can regard both protocols as successful for oestrus synchronization prior to superovulation.

Estradiol usage in cattle is still legal in most countries around the world and it is being used extensively for oestrus synchronization programs (Butler et al. 2012, Manes et al. 2012) while its application is not allowed in food producing animals in the European Union. 
Because of this, the effects of it have to be investigated to improve our scientific knowledge and to compare methods including estradiol with alternatives (e.g. progesterone, GnRHprostaglandin, double-prostaglandin etc.).

In conclusion, both of the progesterone+oestradiol treatments synchronized the oestrus cycle, in FSH superstimulated cows, in this study. Superstimulation started 7 days after synchronization of follicular wave emergence by progesterone+oestradiol valerate or benzoate treatment has resulted in comparable superovulatory response with conventional protocol which is started on day 10 after reference oestrus. That is, any of the progesterone+oestradiol valerate or benzoate protocols can be used for synchronization prior to superstimulation according to the results of this study. Another advantage of the synchronization of the oestrus cycle with progesterone+oestradiol is elimination of need for detecting oestrus or ovulation and waiting 8-12 days after oestrus to initiate gonadotrophin treatments. Findings of this research suggested that, exogenous control of oestrus cycle by using progesterone+oestradiol valerate or benzoate combination as an ear implant or PRID for 9 days, and gonadotrophin injection over a 4 day period initiated on the seventh day of the implant or PRID application, may offer the advantage of initiating superstimulatory treatments at a time that is optimal for follicle recruitment in Brown Swiss cows.

\section{Acknowledgements}

This research was financially supported by the grants from the General Directorate of Agricultural Research, Turkey (Project no: TAGEM/HAYSÜD/02/01/02/01).

\section{References}

Adams GP, Nasser LF, Bo GA, Garcia A, Del Campo MR, Mapletoft RJ (1994) Superovulatory response of ovarian follicle of Wave 1 versus Wave 2 in heifers. Theriogenology 42, 1103-1113

Andrade JCO, Oliveira MAL, Lima PF, Guido SI, Bartolomeu CC, Tenório Filho F, Pina VMR, lunes-Souza TC, Paula NRO, Freitas JCC (2003) The use of steroid hormones in superovulation of Nelore donors at different stages of estrous cycle. Anim Reprod Sci 77, 117-125

Armstrong DT (1993) Recent advances in superovulation in cattle. Theriogenology 39, 7-24

Baracaldo MI, Martinez MF, Adams GP, Mapletoft RJ (2000) Superovulatory response following transvaginal follicle ablation in cattle. Theriogenology 53, 1239-1250

Bo GA, Adams GP, Pierson RA, Mapletoft RJ (1995) Exogenous control of follicular wave emergence in cattle. Theriogenology 43, 31-40

Bó GA, Moreno D, Cutaia L, Baruselli PS (2004) Hormonal manipulation of the estrous cycle in bovine embryo donors and recipients. Acta Sci Vet 32 (Suppl.), 1-22

Bó GA, Baruselli PS, Chesta PM, Martins CM (2006) The timing of ovulation and insemination schedules in superstimulated cattle. Theriogenology 65, 89-101

Bridges PJ, Lewis PE, Wagner WR, Inskeep EK (1999) Licular growth, estrus and pregnancy after fixed-time insemination in beef cows treated with intravaginal progesterone inserts and estradiol benzoate. Theriogenology 52, 573-583

Bungartz L, Niemann H (1994) Assessment of the presence of a dominant follicle and selection of dairy cows suitable for superovulation by a single ultrasound examination. J Reprod Fertil 101, 583-591

Burke CR, Boland MP, Macmillan KL (1999) Ovarian responses to progesterone and oestradiol benzoate administered intravaginally during dioestrus in cattle. Anim Reprod Sci 55, 23-33 
Butler SAA, Phillips NJ, Boe-Hansen GB, Bo GA, Burns BM, Dawson K, McGowan MR (2012) Animal-Level Factors Affecting Ovarian Function in Bos indicus Heifers Treated to Synchronize Ovulation with Intravaginal Progesterone-Releasing Devices and Oestradiol Benzoate. Reprod Domest Anim 47, 463-471

Bülbül B, Ataman MB (2006) Effect of parity on oestrus synchronization success in cows. Revue Méd Vét 157, 158-162

Bülbül B, Kırbaş M, Köse M, Dursun Ş (2010) Investigation of Superovulation Response in Brown Swiss Cows After Synchronization Using Progesterone and Oestradiol Valerate. Kafkas Univ Vet Fak Derg 16, 463-468

Caccia M, Bó GA (1998) Follicle wave emergence following treatment of CIDR-B implanted beef cows with estradiol benzoate and progesterone. Theriogenology 49, 341

Cavalieri J, Rubio I, Kinder JE, Entwistle KW, Fitzpatrick LA (1997) Synchronization of estrus and ovulation and associated endocrine changes in Bos indicus cows. Theriogenology 47, 801-814

Cavalieri J, Hepworth G, Parker KI, Wright PJ, Macmillan KL (2003) Effect of treatment with progesterone and oestradiol when starting treatment with an intravaginal progesterone releasing insert on ovarian follicular development and hormonal concentrations in Holstein cows. Anim Reprod Sci 76, 177-193

Colazo MG, Martínez MF, Small JA, Kastelic JP, Burnley CA, Ward DR, Mapletoft RJ (2005) Effect of estradiol valerate on ovarian follicle dynamics and superovulatory response in progestin-treated cattle. Theriogenology 63, 1454-1468

Diskin MG, Austin EJ, Roche JF (2002) Exogenous hormonal manipulation of ovarian activity in cattle. Domest Anim Endocrinol 23, 211-228

Garcia A, Salaheddine M (2001) Effect of Oestrous Synchronization with Estradiol $17 \beta$ and Progesterone on Follicular Wave Dynamics in Dairy Heifers. Reprod Domest Anim 36, 301-307

Gordon IR (2005) Reproductive Technologies in Farm Animals. CABI Publishing, Cambridge, MA, USA

Hasler JF (1992) Current Status and Potential of Embryo Transfer and Reproductive Technology in Dairy Cattle. J Dairy Sci 75, 2857-2879

Huhtinen M, Rainio V, Aalto J, Bredbacka P, Mäki-Tanila A (1992) Increased ovarian responses in the absence of a dominant follicle in superovulated cows. Theriogenology 37, 457-463

Kafi M, McGowan MR (1997) Factors associated with variation in the superovulatory response of cattle. Anim Reprod Sci 48, 137-157

Lemaster JW, Yelich JV, Kempfer JR, Schrick FN (1999) Ovulation and estrus characteristics in crossbred Brahman heifers treated with an intravaginal progesterone-releasing insert in combination with prostaglandin F2alpha and estradiol benzoate. J Anim Sci 77, 1860-1868

Lindsell CE, Murphy BD, Mapletoft RJ (1986) Superovulatory and endocrine responses in heifers treated with FSH-P at different stages of the estrous cycle. Theriogenology 26, 209-219

Manes J, Aller JF, Callejas SS, Hozbor F, Alberio RH (2012) Influence of the Length of Progestagen Treatment and the Time of Oestradiol Benzoate Application on the Ovulatory Follicle Size and Ovulation Time in Anoestrous and Cyclic Beef Cows. Reprod Domest Anim 47, 412-418

Mapletoft RJ, Martinez MF, Adams GP, Kastelic J, Burnley CA (1999) The effect of estradiol preparation on follicular wave emergence and superovulatory response in norgestomet-implanted cattle. Theriogenology 51,411

Mapletoft RJ, Bó GA (2004) The Control of Ovarian Function for Embryo Transfer: Superstimulation of Cows with Normal or Abnormal Ovarian Function. 23rd World Buiatrics Congress, Québec, Canada

Mapletoft RJ, Bó GA, Baruselli PS (2009) Control of ovarian function for assisted reproductive technologies in cattle. Anim Reprod 6, 114-124

Martinez MF, Adams GP, Kastelic JP, Bergfelt DR, Mapletoft RJ (2000) Induction of follicular wave emergence for estrus synchronization and artificial insemination in heifers. Theriogenology 54, 757-769

Martinez MF, Kastelic JP, Adams GP, Mapletoft RJ (2002) The use of a progesterone-releasing device (CIDR-B) or melengestrol acetate with $\mathrm{GnRH}$, $\mathrm{LH}$, or estradiol benzoate for fixed-time Al in beef heifers. J Anim Sci $80,1746-1751$ 
Mikkola M, Mäntysaari P, Tammiranta N, Peippo J, Taponen J (2005) Effect of dietary protein on embryo recovery rate and quality in superovulated heifers. Anim Reprod Sci 87, 193-202

Nasser LF, Adams GP, Bo GA, Mapletoft RJ (1993) Ovarian superstimulatory response relative to follicular wave emergence in heifers. Theriogenology 40, 713-724

Novotny F, Hajurka J, Macak V (2005) Relationship between blood serum progesterone levels in cattle donors and the yield and quality of embryos. Bull Vet Inst Pulawy 49, 49-52

Penny CD, Lowman BG, Scott NA, Scott PR (1997) Repeated oestrus synchrony and fixed-time artificial insemination in beef cows. Vet Rec 140, 496-498

Price CA, Webb R (1988) Steroid Control of Gonadotropin Secretion and Ovarian Function in Heifers. Endocrinology 122, 2222-2231

Rajamahendran R, Calder MD (1993) Superovulatory responses in dairy cows following ovulation of the dominant follicle of the first wave. Theriogenology 40, 99-109

Ryan DP, Galvin JA, O'Farrell KJ (1999) Comparison of oestrous synchronization regimens for lactating dairy cows. Anim Reprod Sci 56, 153-168

Sato T, Nakada K, Uchiyama Y, Kimura Y, Fujiwara N, Sato Y, Umeda M, Furukawa T (2005) The effect of pretreatment with different doses of $\mathrm{GnRH}$ to synchronize follicular wave on superstimulation of follicular growth in dairy cattle. J Reprod Dev 51, 573-578

Sirois J, Fortune JE (1988) Ovarian follicular dynamics during the estrous cycle in heifers monitored by realtime ultrasonography. Biol Reprod 39, 308-317

Webb R, Armstrong DG (1998) Control of ovarian function; effect of local interactions and environmental influences on follicular turnover in cattle: a review. Livest Prod Sci 53, 95-112

Wright JM (1998) Photographic illustrations of embryo developmental stage and quality codes. In: Stringfellow DA, Seidel SM (eds.) Manual of the International Embryo Transfer Society. IETS, Savoy, Illinois, USA, 167-170 